\title{
INDÍGENAS SATERÉ-MAWÉ/AM E HIXKARYANA/AM EM SOFRIMENTO MENTAL E ÉTICO-POLÍTICO
} Sateré-Mawé/AM and Hixkaryana/AM indigenous people in mental and ethical-political suffering

\author{
Renan Albuquerque \\ Doutor em Sociedade e Cultura na Amazônia \\ Universidade Federal do Amazonas, Manaus, Brasil \\ renanalbuquerque@ufam.edu.br \\ (1) http://orcid.org/0000-0002-3923-9938
}

A lista completa com informações dos autores está no final do artigo

\section{RESUMO}

Partimos de visão spinozana que não dicotomiza corpo e mente e salientamos inferências a respeito de duas etnias indígenas da Amazônia ante a processos psicossociais. Metodologicamente, consideramos historicidade e territorialidade na análise. Ambas podem se vincular a sofrimentos no campo da saúde ou não. As reflexões tiveram o objetivo de considerar cosmovisão e imemorialidades. Concluímos que encontros vividos por povos originários na cidade tendem a lançá-los a condições de sofrimento ético-político, em uma dialética inclusão/exclusão social, diminuindo a conatus dos indígenas, afetando sua saúde e concorrendo para um status de reatividade.

PALAVRAS-CHAVE: Sofrimento mental e ético-político. Povos indígenas Sateré-Mawé/AM. Povos indígenas Hixkaryana/AM. Migração. Amazônia.

\begin{abstract}
We start from a Spinoza vision that does not dichotomize body and mind and emphasize inferences about two indigenous Amazonian ethnic groups facing psychosocial processes. Methodologically, we consider historicity and territoriality in the analysis. Both dimensions can be linked to suffering in health or not. The reflections had the purpose of considering worldview and immemorialities. We conclude that encounters experienced by indigenous peoples in the city tend to impose them into conditions of ethical-political suffering, in a social inclusion/exclusion dialectic, diminishing the indigenous conatus, affecting their health and competing for a status of reactivity.

KEYWORDS: Mental and ethical-political suffering. Indigenous people Sateré-Mawé/AM. Indigenous people Hixkaryana/AM. Migration. Amazon region.
\end{abstract}

\section{INTRODUÇÃO}

Conforme Censo 2010, há no Brasil hoje perto de 818 mil pessoas declaradas ou consideradas indígenas. Destas, 503 mil vivem em áreas rurais e 314 mil em áreas urbanas. Com a Constituição, o Estado reordenou a relação com ameríndios e passou a comprometer-se a "[reconhecer] organização social, costumes, línguas, crenças, tradições e direitos dos originários sobre as terras que tradicionalmente ocupam, competindo à União demarcá-las, proteger e fazer respeitar todos os seus bens" (BRASIL, 1988, art. 231). A partir da Carta Federal, povos tradicionais tiveram respaldo jurídico para manter e reproduzir processos e estatutos socioculturais, após o governo entender que a terra não 
representa só um espaço habitável, mas dominial e impregnado de simbolismo, sedimentado por modos de vida.

Entretanto, terras indígenas (TIs) continuaram sendo invadidas, gerando processos de migração. E quando destacamos a categoria "migração", o fazemos de modo conceitual (CEDEPLAR, 1977; CARVALHO, 1985, 1995; MARTINE, 1987; PACHECO; PATARRA, 1998), com clareza de que estamos entrando em um campo epistemológico delicado para o entendimento de fluxos e trânsitos interespaciais. Abordamos o viés dos Sateré-Mawé/AM e dos Hixkaryana/AM - ambas nações fixadas em Tls do Estado do Amazonas, Norte do Brasil —, etnias que migram para polos urbanos avizinhados a suas terras por diversos motivos, entre eles i) trabalho, ii) estudo e iii) saúde, pois "a migração não começa até que pessoas descobrem que não conseguirão sobreviver com seus meios tradicionais em comunidades de origem" (KLEIN, 2000, p. 13).

O objetivo do texto, porquanto, foi abordar sofrimentos mentais das etnias que se veem forçadas a migrar para espaços urbanos, sendo que tratar a migração pressupôs a perspectiva da interculturalidade (SARRIERA et al., 2005; DEMORGON, 1999 apud DANTAS, 2012). A ponderação foi interdisciplinar e partiu de categorias analíticas do Núcleo de Pesquisa da Dialética Exclusão-Inclusão Social (Nexin), da Pontifícia Universidade Católica de São Paulo (PUC-SP), e da etnografia contextual do Núcleo de Estudos e Pesquisas em Ambientes Amazônicos (Nepam), da Universidade Federal do Amazonas (Ufam). O primeiro grupo de pesquisa é da área da Psicologia Social e o segundo trabalha com vises da Comunicação e da Antropologia.

Discussões no Nexin destacam conceitos de afeto e comum (SPINOZA, 2013, 2014) na análise da desigualdade social (SAWAIA, 1995). Pelo Nepam, a desconstrução de narrativas proposta por Derrida (2004) é trabalhada enquanto perspectiva para se descrever significados de proposituras psicológicas. Encaminhamos a pesquisa sob 0 ponto de vista da construção de indivíduos, coletivos e memórias compartilhadas dos Sateré-Mawé/AM e dos Hixkaryana/AM. Foi nesse desejo do comum que "residiu nossa aventura comunitarista: a energia fundadora do laço social está no desejo de aumentar o conatus, a qual é capaz de explicar porque nenhum momento da história conseguiu anular a capacidade humana de criação de caminhos de fuga" (SAWAIA, 2008, p. 153).

O conatus é uma espécie de critério de avaliação da vida afetiva. Para Spinoza, é positivo aquilo que fortalece o conatus, a potência de agir, e negativo aquilo que o rebaixa. O conatus funciona como um princípio fundamental, pois é mediante seu aumento ou diminuição que o filósofo distingue entre força e fraqueza. 
Nos fortalecemos quando, em nós ou fora de nós, sucede algo de que somos a causa, algo pode ser compreendido clara e distintamente por nós. Ao contrário, padecemos quando se sucede algo ou quando de nossa natureza se segue algo de que não somos senão causa parcial" (SPINOZA, III, p. D2).

Partindo-se do conatus, defendemos que sofrimento mental não se reduz a dores individuais ou experiências negativas pelas quais qualquer ser humano passa, mas sim abrange múltiplas e variantes interseções expostas no processo de desfiliação de mundo das etnias devido dinâmicas enfrentadas na urbe, as quais afetam corpo e alma e são impulsionadas por situações limites (PESSOTTI, 1995, 1996, 1999). O conatus integra o ethos humano e ambos são elementos de esforço do homem em perseverar sua existência, isto é, sua própria essência, recuperando a potência de seu ser.

Assim, foi meta do trabalho analisar sofrimento mental em grupos indígenas questionando-nos: i) o quanto sociedades brancas se esforçam por negar alteridade a grupos étnicos?, ii) quais desdobramentos decorrem do modo de vida das cidades no corpo e na mente de indígenas? e iii) em que medida a desigualdade social, subjacente a estado de descaracterização étnica (migração forçada), explica quadros de sofrimento mental?

Supomos que complexidades socioculturais formadoras de modos de vida têm pouca conexão ante o modelo biomédico usado para tais análises e a consequente caracterização de perturbações psíquicas como patologias tratáveis por viés sintético não responde a conjuntos de saberes e fazeres dos povos originários em perspectiva. A hipótese é que sofrimentos de indígenas na cidade se agravam por marcações do capitalismo, como consumismo, individualismo e intolerância à diversidade.

Dentro do contexto presente do espaço amazônico, o reforço à segregação vem sendo repetido tal e qual uma mutação, uma modificação caótica de sentidos, que marca a floresta, as águas e as cidades do bioma, de modo que a identidade de indígenas da hileia tropical brasileira vem sendo baseada em coisas que não têm regência na natureza e no zênite da vida, formando mecanismos que funcionam como fatores para o desencadeamento de sofrimentos e fricções negativas entre a cultura da $\mathrm{Tl}$ e da cidade.

Sobre as comunidades indígenas trabalhadas (componentes da mesorregião do Baixo Amazonas), no extremo leste da capital do Estado do Amazonas, elas foram escolhidas exatamente pela relação afetiva que temos com a região e com esses povos que nela habitam, pois começamos em 2009 pesquisas com os Sateré-Mawé e os Hixkaryana e desde essa época temos nos lançado em trabalhos de campo. Em 2014, por 
exemplo, nosso livro solo Sofrimento mental de indígenas na Amazônia foi lançado com apoio de fomento internacional. Era o primeiro tomo dos seguintes que viriam. $\mathrm{Na}$ sequência, foram apresentados Brincando de onça e de cutia entre os Sateré-Mawé (2017) e O tacape do diabo e outros instrumentos de predação (2019). Os dois escritos mais recentes tiveram colaboração de Eunice Paiva (in memoriam), Carmen Junqueira (PUC$\mathrm{SP})$ e Gerson Ferreira (Ufam).

\section{REFLEXÕES A PARTIR DA ANTROPOLOGIA E PSICOLOGIA SOCIAL}

Antes de relacionarmos a questão psi às migrações, tomemos como esteio a problemática da decolonialidade, a qual tem alta importância para os povos originários do continente sul-americano desde o século XVI, quando Colombo disse que a Terra estava se apequenando, no sentido territorial, por causa das navegações ibéricas. O Velho Mundo, então em febre civilizatória, criava na época as categorias "irracional" e "colônia" e as aplicava ao que desconhecia. Os nativos da América do Sul, assim, viram-se enredados nesse modelo de conquista. Era o sonho da colonialidade do Velho Mundo tornado real. Um sonho a reboque da lógica expansionista, bélico, que ultrapassava o ato de invasão às terras, devido à violência com que atingiu mente e corpos de nativos.

Foi uma invasão que não se esgotou no passado quinhentista. Pelo contrário, manteve-se e atualmente pode ser estudada em torno do conceito decoloniality, traduzido por decolonialidade (WALSH, 2009). Esse conceito assume rigores diferentes da noção de pós-colonial, que é o que exatamente nos propusemos a tratar no âmbito da migração.

A ideia de decolonialidade transcende a intrusão da colonização, face obscura da modernidade que opera ainda nos dias de hoje em um padrão mundial de poder. A decolonialidade procura implodir conceitos que, no caso amazônico, foram protuberados desde 1542, com Carvajal, passaram por Acuña, cronista da expedição de Pedro Teixeira, em 1637, e tomaram força com o primeiro dos naturalistas no bioma, sob comando do rei da França e consentido pelas Coroa de Espanha e Portugal, trazendo o racionalismo e a ciência, em meados do século XVIII. No entanto, necessitamos distinguir, para almejarmos entendimento, o colonialismo da colonialidade e também a descolonização da decolonialidade.

Por descolonização há que se projetar os processos de superação do colonialismo, sendo correlacionados às lutas anticoloniais no marco dos Estados que resultaram na independência política das antigas colônias (FANON, 1968). A decolonialidade refere-se a 
um complexo estatuto psicossocial e de estrutura humana, que se direciona a transcender a colonialidade e enfrentar o padrão de poder colonial. A ideia da decolonialidade dialoga com o pós-estruturalismo de Foucault, Lacan e Derrida. Em Gramatologia (DERRIDA, 2004) e Psyché: I'invention de autre (DERRIDA, 1987) relativiza-se o conceito presente na teoria estruturalista clássica, disseminada por Lévi-Strauss, ensaiando-se apontar estruturas como mecanismos complexos, mutáveis e não raro como desordenados. Todavia, grandemente prenhes de significados.

De modo que a decolonialidade advém de uma inadaptabilidade a novos espaços de convivência, uma contraposição a eles. Por meio da decolonialidade se busca protestar em favor de processos migratórios que geram apoio familiar, social e estatal. Em si mesma, a decolonialidade, representa atos de resistência contra a fragilização de cuidados parentais e das condições nutricionais e de habitação, estas pioradas com a migração. Migrantes, desta feita, ficam sujeitados à pobreza material e com severos detrimentos morais, o que concorre para estados de inadaptabilidade psicofísica (COSTELLO et al., 2003). Albuquerque e Junqueira (2017), Garnelo et al. (2010), Garnelo e Langdon (2005) e Garnelo (2003) afirmam correlação entre fluxo migracional e saúde mental, no tocante a aspectos socioculturais de enfermidades. O efeito é observado na medida em que o cotidiano dos tradicionais é mediado mais por relações transitórias, projetadas pela funcionalidade de ambientes urbanos, que por identidades construídas historicamente (SPITZER, 1996; SOUZA, 2003; GARNELO e WRIGHT, 2001). "Ao abordar diferenciações de tratamento (sintéticos ou tradicionais), a variável 'migração' é fator com implicação para distúrbios segundo multidimencionalidades e não como condição em si mesma" (ALBUQUERQUE et al., 2016, p. 153).

No caso de Sateré-Mawé e Hixkaryana, a migração teve início em 1967, com a criação da Zona Franca de Manaus, motivada, segundo Diagnóstico Sociodemográfico Participativo da População Sateré-Mawé, pela busca por trabalho assalariado (TEIXEIRA et al., 2009). Além desse fator, estavam também implicadas a necessidade de reconhecimento social e a fuga da tutela do Estado. Nesse ponto, a migração de membros das sociedades nativas das terras baixas da América do Sul (do Baixo Amazonas/AM) passava a ser impactada por sofrimentos mentais componentes da reconfiguração de sua condição espaço-temporal. A vivência a partir da reformulação da vida, agora dentro de uma sociedade mercadocêntrica, imprimiu às etnias contatos dispensáveis, utilitários e casuais, gerando isolamento e na discriminação. 
A observação parece ser sugestiva, visto que mudanças de socioculturas e modos de vida da TI para a cidade, considerando historicidade e violências vivenciadas no contexto urbano, concorrem para desajustes exponenciais. E supomos que relações de poder e expropriação, bem como inclusões forçadas e assistencialistas, são interveniências negativas. O sofrimento de indígenas precisou, portanto, ser analisado pela mediação da dialética exclusão/inclusão (SAWAIA, 2001). Tanto porque a diversidade e a possibilidade de enriquecimento cultural mediante trocas de experiências deveria ser algo producente e não fardo conjuntural. Todavia, rejeitado do convívio comum e refugiado em guetos na urbe, indígenas conviveram com processos conhecidos como apartação - efeito de uma separação em que indivíduos são preteridos do contato humano - recolhendo-se a isolamento sem que isso faça sentido para si.

A crença em narrativas históricas e no papel social que a cosmologia indígena possui é interpretada como frivolidade ou leviandade de velhos, sobretudo conforme percepções de migrantes indígenas, que na cidade experimentam universos não vivenciados em regiões de divisa (RODRIGUES et al., 2012). Esse processo de inclusão pela exclusão social gera "sofrimento [que] é dor mediada pelas injustiças sociais. É o sofrimento de estar submetido à fome e à opressão, e pode não ser sentido como dor por todos" (SAWAIA, 2001, p. 102), mas pelos que sofrem a inclusão perversa.

Considerar, portanto, afetos e emoções no estudo da inclusão "[...] é refletir sobre o 'cuidado' do Estado com seus cidadãos. Eles são indicadores do (des)compromisso com o sofrimento humano, tanto por parte do aparelho estatal quanto da sociedade e do indivíduo" (SAWAIA, 2001, p. 99). Para a autora (cf. SAWAIA, 1999), o sofrimento dos que vivem a inclusão perversa afeta o corpo e a alma, os atormenta mais que a fome. A partir disso, temos que "[...] o sofrimento ético-político retrata a vivência cotidiana das questões sociais dominantes em cada época histórica, especialmente a dor que surge da situação social de ser tratado como inferior, subalterno, sem valor" (SAWAIA, 2001, p. 104).

O sofrimento de indígenas assola corpos e mentes e desregra de forma ético-política a vida. Quando indígenas Sateré-Mawé e Hixkaryana migram para a cidade o modo como vivenciam a urbe e a dinâmica de exclusão-inclusão social projetada no cotidiano ocasiona sofrimento ético-político. Esse sofrimento é produzido a partir de encontros vivenciados na cidade e com a ideologia construtiva a eles então imposta. Em virtude disso, nativos que não "chegam lá", não vencem segundo padrões capitalistas, são derrotados, perdedores e, em razão da incompetência, não conseguem se adequar (SANTOS; NUNES, 2003). 
Tanto o ficar na cidade como o voltar para a TI, agora, passam a gerar sofrimentos. $\mathrm{Na}$ cidade por conta da exclusão-inclusão social. Na terra indígena pelo regresso furtivo, que representa derrota e pequenez. O olhar dos outros sobre a pessoa que regressa é desolador e imprime vergonha. A preocupação com a coletividade, a cosmologia, a contemplação crítica do mundo, que fizeram indígenas superarem obstáculos ao longo da história no bioma Amazônia, são observadas enquanto construções frívolas da realidade, compreendidas tal e qual atividades de pessoas obtusas e pueris, pautadas no ingênuo idealismo. O imaginário indígena é discriminado e sobreposto pelo saber do branco.

O conceito de sofrimento ético-político tem por base a filosofia espinosana, de tendência ontológica, que retira indivíduos da condição de máquina e os reposiciona enquanto seres de potência. Segundo o autor, o corpo humano pode ser afetado de muitas maneiras, pelas quais sua potência de agir é aumentada ou diminuída, enquanto outras tantas não tornam a potência maior nem menor (ESPINOSA, 2013). Esse corpo possui conatus, que é a potencialidade, e responde a afetações de encontros, que podem ser bons ou não.

A potência de conservação é também poder de ser afetado, o que significa que ela, apesar de irreprimível, varia de intensidade, a depender das intersubjetividades que me constituem, isto é, das afecções (affections) que meu corpo e minha mente sofrem nos bons ou maus encontros do passado, do presente e do futuro (SAWAIA, 2008, p. 366).

Afetos são radares indicativos do corpo e da mente, além de funcionarem como motivadores de ação (SAWAIA, 2003). São gerados em encontros com o outro. Encontros são bons quando aumentam a potência de vida e maus quando atrelam a vida à servidão e heteronomia. Relacionando a abordagem ante o cenário de indígenas Sateré-Mawé e Hixkaryana que vivenciam na cidade a exclusão-inclusão social, temos que a imersão em um sistema que privilegia produção e acumulação em detrimento à dignidade e autonomia intelectual concorre para controvérsias e fragmentações a partir do relacionamento com coisas de brancos (KELLY, 2005). Os afetos, porquanto, tendem a deslocar-se nas projeções de vida em espaços urbanos.

Exemplificando o disposto, notemos algumas situações vividas na urbe.

Índia Sateré-Mawé, atendida pelo CAPS/PIN, oriunda de Araticum (comunidade da TI Andirá-Marau), um dos polos étnicos do município de Barreirinha/AM, levava vida ordinária até quando a família lhe organizou casório orientado, como de costume, com membro da comunidade. Antes 
de completar 18 anos não tinha engravidado, o que era considerado atraso em padrões indígenas e por isso uniu-se a um jovem. Com o passar do tempo e a persistência da situação, a pressão aumentou e ela e o marido decidiram vir para a cidade, fugindo das pesadas críticas sobre a infertilidade. Ao se instalarem no reduto urbano de Barreirinha [polo urbano vizinho à TI], as cobranças continuaram. Desta vez, era o companheiro que pedia uma criança o quanto antes, porque precisava retornar à aldeia e compartilhar a notícia com os homens Sateré-Mawé, esvaindo de modo positivo a conturbada retirada para a cidade. Mas, sem mudanças, tempos depois a separação do casal ocorreu devido seguidas tentativas infrutíferas de gravidez. O homem retornou à aldeia de imediato e não houve mais notícias dele. A mulher, ao permanecer na cidade, desenvolveu traços esquizofrênicos marcados por comportamentos bizarros, ansiedade, impulsividade, agressividade e comprometimento do juízo sobre a realidade (RODRIGUES, 2014, p. 101-102).

Um controverso caso a se refletir acerca do sofrimento mental indígena diz respeito a uma pré-adolescente de 12 anos, que havia presenciado o assassinato do pai em uma aldeia Sateré-Mawé [...] Uma hipótese foi baseada na interpretação dos sonhos que a jovem índia disse ter tido, os quais eram situados na sua terra de nascimento, a TI Andirá-Marau. Identificou-se que o falecido pai da menina insistia, em sonho, para que ela voltasse a morar junto dele, cujo corpo estava enterrado na terra indígena, tendo em vista o fato dos dois serem muito apegados outrora. $\mathrm{Na} \mathrm{TI}$, a jovem deveria se submeter à influência xamânica de preceptores Sateré-Mawé para que eles expurgassem dela espíritos maus que a afligiam. O pai teria dito para a menina que havia sido assassinado por vingança e ela devia fazer pajelança com os iniciados espirituais da aldeia de origem caso quisesse continuar viva. Para isso, ela deveria trabalhar para devolver ao espírito do falecido o sossego (RODRIGUES, 2014, p. 106-107).

A partir das narrativas, é possível notar até que ponto o vínculo com a TI permanece independente do motivo da migração. Ademais, a cosmovisão afeta pessoas Sateré-Mawé e Hixkaryana tanto com bons quanto com maus encontros, que em muitos casos se intensificam com a vinda para a cidade, dado que na urbe há ampla individualização e desamparo. O caso é verificável na primeira cena, em que a indígena vivencia medos que se intensificam e a lançam em situações de insegurança. As incidências suprimem suas historicidades, socioculturas e cosmovisões, itens categóricos e formativos de crenças, atitudes, valores e ideologias indígenas.

São corporeidades e mentalidades constantes no bojo das afetações dadas no espaço urbano, sublinhadas para que possamos supor paralelos do sofrimento mental visto que a Tl é lugar de encontros potencializadores e a cidade se diferencia pela exclusãoinclusão social, bem por racismos e discursos de branquitude. Outrossim, conhecimentos indígenas, sejam cosmológicos, parentais ou clânicos, de viés ancestral, enquanto mediadores e fomentadores de natividades para os povos das terras baixas da América do 
Sul, funcionam também inversamente, como componentes de cenários que dificultam a vida urbana.

É a própria ancestralidade e ainda o espaço compartilhado que podem fortalecer e basear esses indivíduos no contexto urbano. Mas laços comunais evidentemente estão enfraquecidos na cidade, o que concorre para maus encontros. Assim, a partir do que debatemos, cabe supor que ansiedade, vergonha, angústia e humilhação (RODRIGUES, 2014) passam a ser, portanto, estopins para caracterizarem emoções da vida indígena no espaço urbano. Diferentemente do que se tende a ser mostrado em Tls, Sateré-Mawé e Hixkaryana, na cidade, vivenciam novas formas de interação sociocultural e econômica, propulsoras de esfacelamentos de sentimentos de comunalidade.

A cidade não aglutina migrantes de origem étnica porque a ideologia dominante nela é a do capital, da cientificidade higienizadora e do ocidentalismo virtuoso, o que gera sofrimento a partir da ideia de "ser diferente". Há de se saber, porém, que estatutos que norteiam as vidas humana e animal em aldeias amazônicas fortalecem a relação com a região onde habitam, sendo que xamãs (pajés) podem orientar essa modificação. Eles guardam a capacidade de compreender, por exemplo, extensas faixas de terra no bioma como áreas comuns para a realização de trabalhos extra-humanos, onde podem ser facilitadas as tomadas de decisão na economia doméstica e na cosmopolítica.

Os xamãs percebem o arranjo de modelos sociais e o ordenamento de recursos da biodiversidade espiritual de forma integrada. E na medida em que desejos, vontades e necessidades moventes do universo existencial nativo impelem a questionamentos esperados para a definição da alma, a intensidade da situação ou a impotência perante podem ser avaliadas por eles.

A função central de especialistas [xamãs] é manter um diálogo constante com seres humanos invisíveis, considerando o cosmo e o meio ambiente equilibrado, com condições habitáveis a seres humanos e demais animais, vegetais e minerais. O esquema de comunicação entre wai-mahsã e humanos se dá através de pessoas preparadas, nos momentos específicos e com conhecimentos específicos. As categorias de yai, kumu ou baya [categorias de xamãs] ficaram escassas e a especialidade de yai [xamã de alta hierarquia que repassa seus conhecimentos de cura] praticamente foi extinta em todo o noroeste amazônico brasileiro. Os kumuã [plural de kumu] ainda existem, mas são poucos. Eles tiveram sua formação antes do alcance em suas comunidades pelos missionários. A maioria, porém, foi atingida em algum momento de sua preparação, sendo forçada a frequentar a escola aí instalada, como foi o caso do meu pai Ovídio Lemos Barreto e meus tios Luciano Barreto e Tarcísio Barreto. Eles são os últimos kumuã Tukano do "sib" huremeri saroró yupuri bubera-porã, moradores do rio Tiquié, na 
comunidade de São Domingos Sávio, em São Gabriel da Cachoeira/AM (João Paulo Barreto Tukano: In portal amazoniareal.com).

Pela falta de yai, os poucos kumuã que restaram se veem forçados a cumprir o papel daqueles, efetuando assim uma dupla função no sistema de comunicação extra-humano e de cura, diagnosticando doenças e realizando bahsesse (benzimentos). Como não há a continuidade na formação de novos especialistas kumuã, podemos dizer que, a exemplo do que aconteceu com os yai, os kumuã estão fadados a desaparecer (João Paulo Barreto Tukano: In portal amazoniareal.com)

No trecho em destaque - que trata a nosso ver de intersecções entre o status da pessoa xamânica, a formação dela e a sua saúde mental para a execução de trabalhos de cura e terapêutica tradicional — podemos acessar os simbolismos nele contidos. São simbolismos que se mostram como códigos, a projetarem entendimentos em função de leituras relacionais do autor, o Tukano João Paulo Barreto, e seus modos de vida. Nós partimos dessa premissa, por exemplo, para notarmos o que não foi dito nessa comunicação: i) primeiro, inferimos que João Paulo constrói ideias sobre sua etnia e as apresenta na relação entre dois conhecimentos distintos, o do branco e o do nativo; ii) segundo, e cremos mais importante, é que o texto tenta decodificar mensagens complexas e de duplo sentido, um humano e outro cósmico, sendo que não foi preciso o autor especificar o significado essencial de cada palavra mencionada e originária do vocabulário Tukano.

A informação e a mensagem são tomadas como interação discursiva, na medida que reúnem a atividade do leitor ante a do escritor. Trata-se da força do conatus spinozano. Quando a interação textual é considerada discursiva é porque há construções de sentidos geradoras de ao menos um referente potencial. Assim, ao vermos com acuidade, temos que o escritor indígena se utilizou de discursos nativos, de seu povo, para construir efeito de pensamento em quem o lê, dando à pessoa a possibilidade de montar um sentido simbolicamente, já que ele não se encontra acabado, dado, apesar de apresentar um contexto imediato com diversas informações. Assim, existe a necessidade da compreensão não somente do suporte simbólico disponibilizado, mas também de elementos ideológicos dos Tukano.

Trazendo o disposto para nossa seara de estudo, João Paulo Barreto, mesmo sem opinar diretamente acerca do comum, destaca a permanência de práticas ancestrais xamânicas por meio dos mesmos afetos categoriais por nós tratados e dentro de uma paradigmática situação de deslocamento temporal. Porque investigar a ideia de "comum" para um ameríndio amazônico não é intentar ao desvelo de sua identidade indígena 
mediante uma atribuição de quem é quem. Tem a ver com a maneira a qual o coletivo concebe formas de expressão e as remete a afirmativas parentais, clânicas e consanguíneas. Trata-se menos de ponderar sobre quem é ou não esse nativo migrante a partir de uma narrativa, mas sim de contextualizá-lo segundo práticas do cotidiano.

As considerações, aparentemente antagônicas, bem como as possibilidades de compreensão de fenômenos psicossociais mediante a "diplomacia espiritual xamanística" (ALBUQUERQUE e JUNQUEIRA, 2017, p. 128), apontam que a correlação entre ambiente externo e sofrimentos mentais de indígenas se mantém persistente, não sem variantes intervenientes, mas pode ser interpretada por agentes da pajelança. Seja por vieses socioeconômicos ou cosmopolíticos, a associação de multifatores e a mensuração do problema são investigações em progresso, assim entendemos, desde que foi lançado o livro Natureza, doenças, medicina e remédios dos índios brasileiros, do naturalista alemão Carl Friedrich Philipp Von Martius (1794-1868), em 1844.

Relatos pioneiros acerca do sofrimento mental de populações indígenas foram discutidos via aspectos biossociais, equilibrados no conhecimento de época sobre doenças particulares a esse estado. Foram pesquisados no livro temperamento, comportamento coletivo, anatomia, dieta, longevidade, terapia tradicional, valores espirituais, ritos e rituais. É obra proveniente de experimentos de campo, que apresenta observações entremeadas a teorias vigentes no início do século XIX. Porém, não parece ser coerente reduzir aspectos da saúde apenas a indivíduos em si mesmos.

Um caminho fértil é destacar que há nítidos relacionamentos com o mundo externo (social), e, no caso de nossas inferências, ao mundo urbano (urbes pequenas) amazônico, capitalista e segregador. Assim, partindo de visão espinosana, entendemos que "ter saúde é estar apto a afetar e ser afetado por outros corpos em bons ou maus momentos. Sua contribuição é o deslocamento do político para o campo da ética e desta para o campo das emoções" (SAWAIA, 2003, p. 92). Ou seja, sofrimentos mentais oriundos da migração Sateré-Mawé e Hixkaryana não podem ser reduzidos a algo individual ou "apenas da mente". Estão ligados, cremos, ao externo do eu da mesma forma que a indivíduos, a vivências, a histórias, a cosmovisões e a coletividades.

Nesse sentido, voltemos à temática do comum para afirmar que a categoria se torna força potencializadora de indivíduos na cidade e reforça, enquanto sentimento, enfrentamento a investidas do Estado, do mercado e da forma como a cidade afeta aos indivíduos. Por meio dos bons encontros spinozanos, indígenas têm a potência para enfrentar e conquistar espaços de vivência compartilhada da cidade e o comum se torna 
uma forma disso. Dado o exposto, apostamos que é possível entender "a saúde não como totalidade em si, nem uma relação imediata com a doença ou um estado definido biologicamente. Ela é a possibilidade de ter esperança e potencializar esta esperança em ação" (SAWAIA, 2003, p. 93).

Interessa verificar a importância das emoções e como indígenas estão afetando e sendo afetados por outros corpos. Olhar para o disposto é olhar para encontros e atravessamentos sociais vividos por indivíduos que, no caso, além da cidade, também vivenciam memórias de uma história de violência e genocídio vinculada a sua terra primordial. Com isto, as violências empregadas pelo branco, bem como pelo capital, além do desmerecimento da formação psicossocial indígena e o enaltecimento ao consumo, lançam os povos Sateré-Mawé e Hixkaryana a uma vida de pobreza e exclusão.

Esse cenário afeta o corpo pelo discurso ideológico da branquitude, do cientificismo e do racionalismo, e a mente por biocumulatividade. $\mathrm{O}$ ato de andar pela cidade, transitar em espaços e vivenciar tradições e crenças, mesmo no contexto urbano, deixa de fazer parte da composição da sociabilidade nativa, pois se perde em efeito e ocasiona um mau encontro. Como resultado, a sociedade branca deixa de entender indígenas em sua totalidade. E entender povos indígenas é levar em conta terra, ethos, compadrios, parentelas e metaformatividades animais, além de saberes e curas xamanísticas.

A vida dos Tukano do Alto Rio Negro/AM, sobremaneira no bojo das espiritualidades, pode ser correlacionada com funções não corpóreas de Sateré-Mawé e Hixkaryana. Ou seja, os três povos originários possuem similaridades dentro dessa conjuntura. Assim, citamos o exemplo de João Paulo Barreto e o tomamos em paralelo porque consideramos importante a problemática da saúde mental de migrantes étnicos no Baixo Amazonas/AM (escopo do estudo). E o fizemos porque almejamos dar visibilidade a bases históricas em relação a uma questão etnocultural ampla, integrante dos problemas da atualidade, os quais apontam que as sociedades das terras baixas da América do Sul são exemplo de representantes de uma comunicação geral baseada em cosmologias integradoras.

\section{CONCLUSÃO: O COMUM E OS POVOS ORIGINÁRIOS}

Partimos de uma visão espinozana que não dicotomiza corpo e mente, entendendo pessoas como unas, seres de potência, trabalhando a ideia de conatus e ethos como integrantes da problemática do sofrimento mental de povos originários em fluxo migracional aldeia-cidade. A partir disso, salientamos a importância da observação e da análise 
propiciadas por encontros vivenciados (potência dos encontros), visto que, a partir deles, conforme Espinosa (2013), sua conatus é expandida ou não. E por isso a importância do comum nessa temática como conjuntura significativa do ethos.

No estudo, concluímos que encontros vividos por povos originários na cidade tendem a lançá-los a condições de sofrimento ético-político, fruto da dialética inclusão-exclusão social. Isto ocasiona a diminuição da conatus e, por conseguinte, afeta a saúde deles, concorrendo para um status de reatividade, porque esses encontros são diferentes em terras indígenas, pois ali existem locais de potência, ancestralidade e cosmogonia, ou seja, locais memoriais ao comum. Já a cidade, capitalista, esfacela esse comum, reproduzindo individualismos, competições e afetações.

Foi necessário considerar, para essa conclusão, historicidade e territorialidade na análise, além de pontuar a problemática da decolonialidade em certo sentido. Elas podem se vincular a sofrimentos, seja no campo da saúde ou não. No contexto da urbe, para povos originários, o comum é forma de potência e de resistência, visto que é por meio dele que esses povos podem enfrentar vivências controversas. Com isso, promover bons encontros é também enfrentar desigualdades sociais existente nas cidades com a ótica para os afetos.

Concluímos ainda ter sido importante trazer Spinoza ao debate porque o filósofo já nos tempos passados foi pioneiro em cindir com a ideia onipotente de um Deus determinista e fortalecer os laços relacionais pessoa-sociedade, o que veio ao encontro das questões tratadas tendo como foco a migração indígena aldeia-cidade. Essas questões têm forte dependência contingencial e histórica, para além de dimensões metafísicas.

As reflexões objetivaram apontar caminhos para a práxis junto a povos originários, considerando cosmovisão e imemorialidades e tendo o comum como norte para a potência e o fortalecimento psicofísico frente a violências do Estado e do mercado. Nisso também se projeta a potência dos encontros entre as áreas aqui apresentadas, dialogantes com psicologia social, comunicação e antropologia, que juntas podem ensaiar explicações sobre o comum junto a esses povos sul-americanos de primeira nação.

\section{REFERÊNCIAS}

ALBUQUERQUE, Renan e JUNQUEIRA, Carmen. Brincando de onça e de cutias entre os Sateré-Mawé. Editora da Universidade Federal do Amazonas (EDUA/AM), 232 p, 2017.

ALBUQUERQUE, Renan; FERREIRA, Ricardo; SCHWEICKARDT, Júlio, CORDEIRO, Maria. Casos de "roubo de sombra" em fronteiras interétnicas: sofrimento mental no Baixo Amazonas/AM, Amazônia Central. Revista Comunnicare, Volume 16, №1, 1\%/2016. 
BRASIL. Constituição da República Federativa do Brasil, 1988.

CARVALHO, José Alberto Magno de. Estimativas indiretas e dados sobre migrações: uma avaliação conceitual e metodológica das informações censitárias recentes. Revista Brasileira de Campinas, v. 2, n^1, p. 31-73, jan-jun, 1985.

CARVALHO, José Alberto Magno de; FERNANDES, Fernando. Migrações Internas no Brasil 1960-1980. Belo Horizonte: CEDEPLAR, (mimeo), 1995.

CEDEPLAR/SUDAM. Migrações Internas na Região Noite: estudo de campo da Região de Marabá. Belo Horizonte, 1977.

COSTELLO, Jane; COMPTON, Scott; KEELER, Gordon; ANGOLD, Adrian. Relationships between poverty and psychopathology: a natural experiment. Journal of American Medical Association, vol. 290, n. 15, oct, 2003.

DANTAS, Sylvia. Para uma compreensão intercultural da realidade. In: DANTAS, Sylvia D. (Org) Diálogos Interculturais: Reflexões Interdisciplinares e Intervenções Psicossociais. São Paulo: Instituto de Estudos Avançados da Universidade de São Paulo, 2012.

DERRIDA, Jacques. Gramatologia. São Paulo, Perspectiva, 2004.

DERRIDA, Jacques. Psyché: L’invention de l'autre. Paris: Galilée, 1987.

FANON, Frantz. Os condenados da terra. Rio de Janeiro: Civilização Brasileira, 1968.

GARNELO, Luiza et al. Ambiente, saúde e estratégias de territorialização entre os índios Baniwa do Alto Rio Negro. Tellus, Campo Grande, n. 18, p. 39-63, 2010.

GARNELO, Luiza; LANGDON, Jean. A antropologia e a reformulação das práticas sanitárias na atenção básica à saúde. In: Minayo, Maria Cecília; Coimbra Jr., Carlos (Org.). Críticas e atuantes: ciências sociais e humanas em saúde na América Latina. Rio de Janeiro: Ed. Fiocruz. p.139-150, 2005.

GARNELO, Luiza. Poder, hierarquia e reciprocidade: saúde e harmonia entre os Baniwa do Alto Rio Negro. Rio de Janeiro: Ed. Fiocruz, 2003.

GARNELO, Luiza, WRIGHT, Robin. Doença, cura e serviços de saúde. Representações, práticas e demandas Baniwa. Cadernos de Saúde Pública (ENSP. Impresso), Rio de Janeiro, v. 17, n.2, p. 273-284, 2001.

KELLY, José. Notas para uma teoria do "virar branco". Mana 11(1): 201-234, 2005.

MARTINE, George. Migração e metropolização. São Paulo em Perspectiva, São Paulo, Fundação Seade, v. 1, n. 2, p. 28-31, jul-set, 1987.

PACHECO, Carlos Américo, PATARRA, Neide. Movimentos migratórios anos 80: novos padrões? In: Encontro Nacional Sobre Migração. Anais... Curitiba: Abep/lpardes, 1998. 
PESSOTTI, Isaias. A loucura e as épocas. 2. ed. São Paulo: Ed. 34, 1995.

PESSOTTI, Isaias. O século dos manicômios. São Paulo: Ed. 34, 1996.

PESSOTTI, Isaias. Os nomes da loucura. São Paulo: Ed. 34, 1999.

RODRIGUES, Renan Albuquerque, PAIVA, Ignês, CATALÃO JÚNIOR, Antonio. A prática construtiva de um Projeto Político-Pedagógico junto a índios Sateré-Mawé, na Amazônia Central. Muitas Vozes, v. 1, p. 271-285, 2012.

RODRIGUES, Renan Albuquerque. Sofrimento mental de indígenas na Amazônia. Editora Valer, 2014.

SANTOS, Boaventura de Souza, NUNES, José. 2003. Introdução: para ampliar o cânone do reconhecimento, da diferença e da igualdade. In: Santos, Boaventura de Sousa (Org.). Reconhecer para libertar: os caminhos do cosmopolitismo multicultural. Rio de Janeiro: Civilização Brasileira, p. 25-68.

SAWAIA, Bader. O ofício da psicologia social à luz da ideia reguladora de sujeito: da eficácia da ação à estética da existência. In Zanella, A., et al., (org). Psicologia e práticas sociais. Rio de Janeiro: Centro Edelstein de Pesquisas Sociais, p. 67-79, 2008.

SAWAIA, Bader. O sentido ético-político da saúde na era do triunfo da tecnobiologia e do relativismo. In: Goldenberg, P., Marsiglia, R. e Gomes, M. (Orgs). O Clássico e o Novo: tendências, objetos e abordagens em ciências sociais e saúde. Rio de Janeiro: Editora Fiocruz, p. 83-96, 2003.

SAWAIA, Bader. (Org). As artimanhas da exclusão: análise psicossocial e ética da desigualdade social. 2 ed. Petrópolis: Vozes, 2001.

SAWAIA, Bader. Comunidade como ética e estética da existência: uma reflexão mediada pelo conceito de identidade. Psyque, vol. 8, n. 1, p. 19-25, 1999.

SAWAIA, Bader. O calor do lugar: segregação urbana e identidade. São Paulo em Perspectiva, vol. 9, n. 2, 1995.

SPINOZA, Baruch. Ética. 2 ed. Belo Horizonte: Autêntica, 2013.

SPINOZA, Baruch. Obra Completa I: (Breve) tratado e outros escritos. Organização J. Guinsburg, Newton Cunha, Roberto Romano. São Paulo: Perspectiva, 2014.

SOUZA, Maximiliano. Atendimento psiquiátrico a pacientes indígenas no Estado do Amazonas. Revista de Psiquiatria Clínica, São Paulo, v. 30, n. 1, p. 38-39, 2003.

TEIXEIRA, Pery. et al. Migração do povo indígena Sateré-Mawé em dois contextos urbanos distintos na Amazônia. Caderno CRH, Salvador, v. 22, n. 57, 2009.

WALSH, Catherine. Interculturalidad, Estado, Sociedad: Luchas (de)coloniales de nuestra época. Universidad Andina Simón Bolivar, Ediciones Abya-Yala, Quito, 2009. In. 


\title{
NOTAS
}

\section{Renan Albuquerque}

Doutor em Sociedade e Cultura na Amazônia pela Universidade Federal do Amazonas (UFAM), com estágio Pós-

Doutoral em Antropologia pela PUC-SP. Professor Adjunto IV da UFAM e atualmente coordena o Mestrado em

Ciências da Comunicação da Faculdade de Informação e Comunicação (FIC/UFAM), Manaus, Brasil.

renanalbuquerque@ufam.edu.br

(1) http://orcid.org/0000-0002-3923-9938

\section{Endereço de correspondência do principal autor}

Av. Gen. Rodrigo Octávio, 6200, Coroado I, Setor Norte, Campus Universitário, Faculdade de Informação e Comunicação. CEP 69080-900, Manaus/AM, Brasil.

\section{AGRADECIMENTOS}

Não se aplica.

\author{
CONTRIBUIÇÃO DE AUTORIA \\ Concepção e elaboração do manuscrito: R. Albuquerque \\ Coleta de dados: R. Albuquerque \\ Análise de dados: R. Albuquerque \\ Discussão dos resultados: R. Albuquerque \\ Revisão e aprovação: R. Albuquerque
}

\section{CONJUNTO DE DADOS DE PESQUISA}

O conjunto de dados que dá suporte aos resultados deste estudo não está disponível publicamente.

\section{FINANCIAMENTO}

Pontifícia Universidade Católica de São Paulo (PUC-SP).

\section{CONSENTIMENTO DE USO DE IMAGEM}

Não se aplica

\section{APROVAÇÃO DE COMITÊ DE ÉTICA EM PESQUISA}

O projeto foi aprovado no âmbito do Edital PIPEq/PUC-SP 5601/2019, obtendo financiamento por meio do AuxGP/PUCSP.

\section{CONFLITO DE INTERESSES}

Não se aplica.

LICENÇA DE USO - uso exclusivo da revista

Os autores cedem à Revista Internacional Interdisciplinar INTERthesis os direitos exclusivos de primeira publicação, com o trabalho simultaneamente licenciado sob a Licença Creative Commons Attribution (CC BY) 4.0 International. Estra licença permite que terceiros remixem, adaptem e criem a partir do trabalho publicado, atribuindo o devido crédito de autoria e publicação inicial neste periódico. Os autores têm autorização para assumir contratos adicionais separadamente, para distribuição não exclusiva da versão do trabalho publicada neste periódico (ex.: publicar em repositório institucional, em site pessoal, publicar uma tradução, ou como capítulo de livro), com reconhecimento de autoria e publicação inicial neste periódico.

PUBLISHER - uso exclusivo da revista

Universidade Federal de Santa Catarina. Programa de Pós-graduação Interdisciplinar em Ciências Humanas. Publicação no Portal de Periódicos UFSC. As ideias expressadas neste artigo são de responsabilidade de seus autores, não representando, necessariamente, a opinião dos editores ou da universidade.

EDITORES - uso exclusivo da revista

Javier Ignacio Vernal, Silmara Cimbalista e Selvino José Assmann (In Memoriam).

EDITOR ASSISTENTE - Eixo temático: “Amazônia: povos, conflitos e preservação” Luiz Barp 
HISTÓRICO - uso exclusivo da revista

Recebido em: 18-11-2019 - Aprovado em: 10-03-2020 - Publicado em: 13-04-2020 